\title{
Visualizing the drivers of an effective health workforce: a detailed, interactive logic model
}

Serena Sonderegger ${ }^{1 *} \mathbb{D}$, Sara Bennett ${ }^{1}$, Veena Sriram ${ }^{2}$, Ummekulsoom Lalani ${ }^{1}$, Shreya Hariyani ${ }^{1}$

and Timothy Roberton ${ }^{1}$

\begin{abstract}
Background: A strong health workforce is a key building block of a well-functioning health system. To achieve health systems goals, policymakers need information on what works to improve and sustain health workforce performance. Most frameworks on health workforce planning and policymaking are high-level and conceptual, and do not provide a structure for synthesizing the growing body of empirical literature on the effectiveness of strategies to strengthen human resources for health $(\mathrm{HRH})$ ). Our aim is to create a detailed, interactive logic model to map HRH evidence and inform policy development and decision-making.
\end{abstract}

Methods: We reviewed existing conceptual frameworks and models on health workforce planning and policymaking. We included frameworks that were: (1) visual, (2) comprehensive (not concentrated on specific outcomes or strategies), and (3) designed to support decision-making. We compared and synthesized the frameworks to develop a detailed logic model and interactive evidence visualization tool.

Results: Ten frameworks met our inclusion criteria. The resulting logic model, available at hrhvisualizer.org, allows for visualization of high-level linkages as well as a detailed understanding of the factors that affect health workforce outcomes. HRH data and governance systems interact with the context to affect how human resource policies are formulated and implemented. These policies affect HRH processes and strategies that influence health workforce outcomes and contribute to the overarching health systems goals of clinical quality, responsiveness, efficiency, and coverage. Unlike existing conceptual frameworks, this logic model has been operationalized in a highly visual, interactive platform that can be used to map the research informing policies and illuminating their underlying mechanisms.

Conclusions: The interactive logic model presented in this paper will allow for comprehensive mapping of literature around effective strategies to strengthen $\mathrm{HRH}$. It can aid researchers in communicating with policymakers about the evidence behind policy questions, thus supporting the translation of evidence to policy.

Keywords: Health policy, Human resources for health, Health workforce, Health services administration and management, Governance, Evidence-to-policy, Framework, Logic model

\section{Background}

In health systems research, practice, and policy over the past two decades, various goals have consistently been articulated-including improved health, responsiveness,

*Correspondence: ssonder4@jhu.edu

1 Johns Hopkins Bloomberg School of Public Health, 615 N. Wolfe Street, Baltimore, MD 21205, USA

Full list of author information is available at the end of the article efficiency, and social and financial risk protection [1]. As one of the health systems "building blocks", the health workforce plays an indispensable role in achieving these goals [2-4]. Globally, there is increased focus on expanding the availability, accessibility, acceptability, coverage, and quality of the health workforce as a critical step to achieving universal health coverage (UHC) and the Sustainable Development Goals [2]. Strengthening the evidence base for workforce policies and the uptake of original author(s) and the source, provide a link to the Creative Commons licence, and indicate if changes were made. The images or other third party material in this article are included in the article's Creative Commons licence, unless indicated otherwise in a credit line to the material. If material is not included in the article's Creative Commons licence and your intended use is not permitted by statutory regulation or exceeds the permitted use, you will need to obtain permission directly from the copyright holder. To view a copy of this licence, visit http://creativecommons.org/licenses/by/4.0/. The Creative Commons Public Domain Dedication waiver (http://creativeco mmons.org/publicdomain/zero/1.0/) applies to the data made available in this article, unless otherwise stated in a credit line to the data. 
evidence-informed policies are critical to achieving these goals [2].

In recent years, researchers have made strides in examining issues such as recruitment strategies, training, supervision, and outcomes such as retention, motivation, and distribution [5-7]. To make this growing literature more accessible to policymakers, frameworks can help consolidate research to demonstrate factors affecting workforce outcomes, strength of linkages, and interrelationships that impact the health workforce as part of a robust health system. In turn, such a visual consolidation of evidence can provide researchers feedback on areas with existing evidence and those requiring greater attention. Ultimately, this could create a two-way interaction between researchers and policymakers facilitating the evidence-to-policy translation process in the context of human resources for health (HRH) policymaking.

There are multiple frameworks that explore the determinants of health workforce performance [8-13]. Most include some elements of contextual factors, health system building blocks, planning and implementation, and processes across the HRH lifecycle leading to $\mathrm{HRH}$ goals-but portray these elements and their relationships in different ways. The majority of frameworks are developed for decision-makers (e.g., government officials or leaders), showing how they can influence HRH outcomes to achieve health system goals-for example, through influencing health labor markets $[9,14]$ or using HRH "action fields" to advance policy objectives [8].

While these frameworks provide useful guidance on HRH policies and policymaking, they are generally highlevel and conceptual. They show broad causal pathways, but most do not show causal relationships between specific factors, or the strength of the relationships between these factors. We have growing evidence on these specific relationships, sometimes including measurement of effects $[7,15,16]$. Other HRH frameworks focus on specific workforce outcomes or cadres of health workers [17, 18] without overarching interactions across domains.

In this paper, we present a detailed logic model that synthesizes existing HRH conceptual frameworks to (1) depict how upstream context, governance, and policy decisions affect the HRH lifecycle and downstream HRH outcomes and impacts, and (2) provide a base for mapping the evidence for these interactions, allowing for exploration of research and policy pathways. To bring the logic model to life, we use an interactive visualization platform that allows the logic model to be expanded and collapsed to show different levels of detail. Although such platforms are still new, they have many potential applications; for example, the Lives Saved Tool (LiST) Visualizer allows users to explore the relationships captured by the LiST modeling tool-which uses mathematical modeling to estimate the impact of changes in intervention coverage on mortality in low- and middle-income countries (LMICs) [19]. While in the past, a comprehensive yet detailed model showing specific relationships and their strength would not have been feasible given technological and space constraints, an interactive online "visualizer" tool addresses these barriers. An interactive tool also allows for overlaying other data on the model; for example, allowing users to click on elements of the model to explore the available evidence and appropriate indicators.

We see potential for this type of interactive tool to expand the traditional concept of a framework or logic model, creating possibilities for otherwise static images to become portals to explore data [20,21]. In the context of $\mathrm{HRH}$, this tool could support the evidence-to-policy translation process, synthesizing research in a visually appealing and accessible way for policymakers and practitioners. It could also help bridge the gap between academia, policy, and practice, while advancing global health workforce goals [2].

This paper first outlines the methods used for developing the logic model and visualizer tool. Next, we describe the conceptual frameworks analyzed in developing the logic model and present the resulting high-level and detailed logic model. Finally, we discuss the utility of the visualizer in consolidating evidence and answering policy questions.

\section{Methods}

We used a multi-stage process that included: (1) searching for existing $\mathrm{HRH}$ frameworks and selecting those that fit inclusion criteria; (2) reviewing the resulting frameworks and synthesizing their contents into a detailed logic model; and (3) adapting this multi-level logic model into an interactive platform for visualizing relationships and evidence.

\section{Search for existing frameworks}

We conducted a targeted literature search to identify relevant conceptual frameworks. Initially, the research team identified existing frameworks from their prior knowledge and experience. Seven conceptual frameworks were identified and used as a starting point for our analysis, as well as to develop search terms for further exploration.

We searched PubMed, Google Scholar, and Google Image, using combinations of "human resources for health" or "health workforce development" or "health labor market", and "framework" or "conceptual model" or "conceptual framework" or "theoretical framework". In addition, we reviewed websites consolidating guidance on $\mathrm{HRH}$, including the Capacity Project resource page 
[22], WHO Health Workforce resource page [23], and CapacityPlus HRH Global Resource Center [24].

We used the following inclusion and exclusion criteria. Inclusion criteria:

- Comprehensive frameworks aimed at supporting holistic decision-making around HRH policy, markets, and systems.

- Oriented towards improving health systems functioning and population health.

- Specific to the health sector.

- Includes a visual model (graphic conceptual framework).

Exclusion criteria:

- Narrowly focused frameworks targeting specific policy concerns (e.g. rural retention, balancing skill-mix of cadres, or external migration).

- Stepwise tools, guidelines, workforce projection equations, or similar, targeting specific components of HRH planning or policies.

- Frameworks focusing on a specific region or country that cannot be easily translated to other contexts.

- Close adaptations of frameworks already included in our analysis (to minimize overlap).

No date restrictions were applied.

\section{Review and synthesis}

Information on the selected frameworks was collated and analyzed in an Excel matrix. Thematic categories were developed based on broad similarities across the frameworks: context and determinants; policy or action levers; health and HRH strategy planning and governance; processes across the HRH lifecycle; and ultimate goals and outcomes of HRH inputs and processes. We then mapped the different factors and subfactors for each conceptual framework into these thematic categories and sub-sections.

Analyzing the overlap and variations within the matrix, we synthesized categories, components, and relationships depicted in the conceptual frameworks into an initial comprehensive logic model. The high-level logic model visually depicts broad "hierarchical levels", showing how upstream contextual factors, governance, and policy decisions affect processes across the HRH lifecycle and downstream HRH outcomes and impacts. The detailed logic model shows subcomponents and considerations within each. In addition to the frameworks identified in our search, we drew upon supplementary empirical research and literature to detail each component of our model (e.g., governance, political factors, etc.).

We also validated the initial model with two academic experts experienced in HRH policy-development and practice. These experts provided feedback on the layout, components, and potential future uses for the model.

\section{Interactive visualizer}

We developed an interactive version of the model with the following features:

- An online software application, centered around a visual graphic of the logic model, built using scalable vector graphics (SVG) common to many web pages.

- Visualization of the logic model components (as "text boxes") with nested subcomponents ("boxes within boxes"), with the ability to expand and collapse components.

- Visualization of relationships and interactions between components and subcomponents across different levels (i.e., upstream vs. downstream) using arrows.

- Ability to isolate impact pathways and relationships within the model, by focusing in on specific desired outcomes, interventions, or components and subcomponents.

- Ability to overlay information (e.g., research publications, indicators) onto components and subcomponents, so that users can click to reveal embedded references to empirical literature.

\section{Results}

Our search and review process resulted in 10 conceptual frameworks on $\mathrm{HRH}$ that fit the inclusion and exclusion criteria. In this section, we (1) briefly outline these 10 frameworks and how they were incorporated into the resulting logic model, and (2) detail the resulting logic model developed based on these conceptual frameworks.

\section{Search results}

The research team initially identified seven conceptual frameworks from the team's existing knowledge. Six of these were included in the final analysis, while one did not meet inclusion and exclusion criteria. Our subsequent broader search yielded 36,792 results. Of these, the Google Scholar results yielded the highest number (between 160 and 20,400 per search). To manage the number of publications in the initial extraction, we reviewed the first $\sim 150$ titles for each search (total of 1316 articles across searches). Publications with titles that appeared to fit the inclusion and exclusion criteria 
were selected for further review (80 publications). We reviewed these 80 publication abstracts and found that 76 publications did not meet inclusion and exclusion criteria. Where frameworks were adaptations of other frameworks, we selected the most comprehensive framework for inclusion, or included both if they were sufficiently different in terms of components and focus. For example, $[10,25]$ are considered the same framework, while $[8,12$, 26] are sufficiently different to warrant inclusion of all three. Four additional frameworks were identified, leading to a total of 10 frameworks summarized in Table 1. Figure 1 describes the selection strategy.

The 10 selected frameworks have similar high-level elements, but differ in level of detail, layout, and depicted relationships. Overlapping elements include contextual factors, health systems building blocks, HRH policy planning and implementation, processes that influence outcomes across the HRH lifecycle, and intermediate and ultimate $\mathrm{HRH}$ outcomes.

The frameworks differ in perspective, focus, and the outcomes they describe. Some see the labor market and/or individuals within the labor market as drivers of health workforce outcomes, and show how policies can be implemented to influence individual choices, the labor market, and/or the education sector to achieve desired health workforce size and quality $[9,11,13,14,27]$. Others look at more "top-down" approaches regarding HRH financing, planning, and policymaking $[8,12,26]$. Finally, some focus on organizational and contextual factors and management strategies that improve performance and outcomes [10, 28].

In addition to the frameworks, we identified several publications that did not meet our criteria (particularly that of a visual framework), but nonetheless provided insights about HRH governance and policies that informed our logic model. They are referenced in the logic model explanation that follows.

\section{Logic model}

We adapted the common elements and relationships depicted in the frameworks into a detailed, interactive logic model, available at hrhvisualizer.org [29]. The final model has five columns with components (17), subcomponents (44), and interactions between them, which allows for high-level and detailed exploration of the model elements. The arrows in the model are directed and causality flows from left to right. We intentionally chose to create the model as a directed acyclic graph (DAG) and to minimize feedback loops. Although other models emphasize causal loops [30,31], our goal was to show how upstream factors affect downstream outcomes. Although in reality these relationships are complex, our approach makes it easier to identify the "drivers" of an effective HRH workforce. Without this DAG constraint, the complexity of the model might overwhelm its clarifying purpose.

The high-level logic model, shown in Fig. 2a, includes only the top-level components, and the broad linkages across columns. Each of the top-level components has additional subcomponents, which can be seen in Fig. $2 \mathrm{~b}$. The detailed model dives deeper and allows the user to see granular relationships between components and subcomponents.

Each of the columns, components, and subcomponents are described below.

Column 1. Contextual factors: these include factors within the broader societal, economic, political, and policy environment that affect downstream decisions and outcomes within the health and HRH system [32]. We categorized contextual factors into three larger components, following adaptation of the Political, Economic, Social, Technical, Legal, and Environmental (PESTLE) analysis framework.

- Social, legal, environmental, and epidemiological factors: the legal system (regulation and law enforcement); the basic and professional educational system; epidemiological and environmental factors that affect population distribution and health needs; levels of equity and/or marginalization of different groups (e.g., socioeconomic, gender, race, ethnicity, education, etc.), and levels of corruption [33].

- Economic factors: strength of the economy, nature of health markets-including levels of care, financing, and service provision-and larger labor market forces that affect health workforce distribution, public and private decision-making, and $\mathrm{HRH}$ outcomes.

- Political factors: decentralization of power and decision-making; the type and capacity of political regime in power and its level of "political entrenchment"; and the influence governmental and non-governmental stakeholders have on policy adoption and implementation [34].

Column 2. Health system factors: effective governance institutions, organizations, practices, and capacities for management, decision-making, and data use in policymaking support sound policy development and implementation. Specific areas of health and HRH systems and processes include:

- HRH system governance: leadership, processes, and capacities for governing HRH systems. This includes: individual, organizational, and systemic capacity for management and decision-making; collabora- 


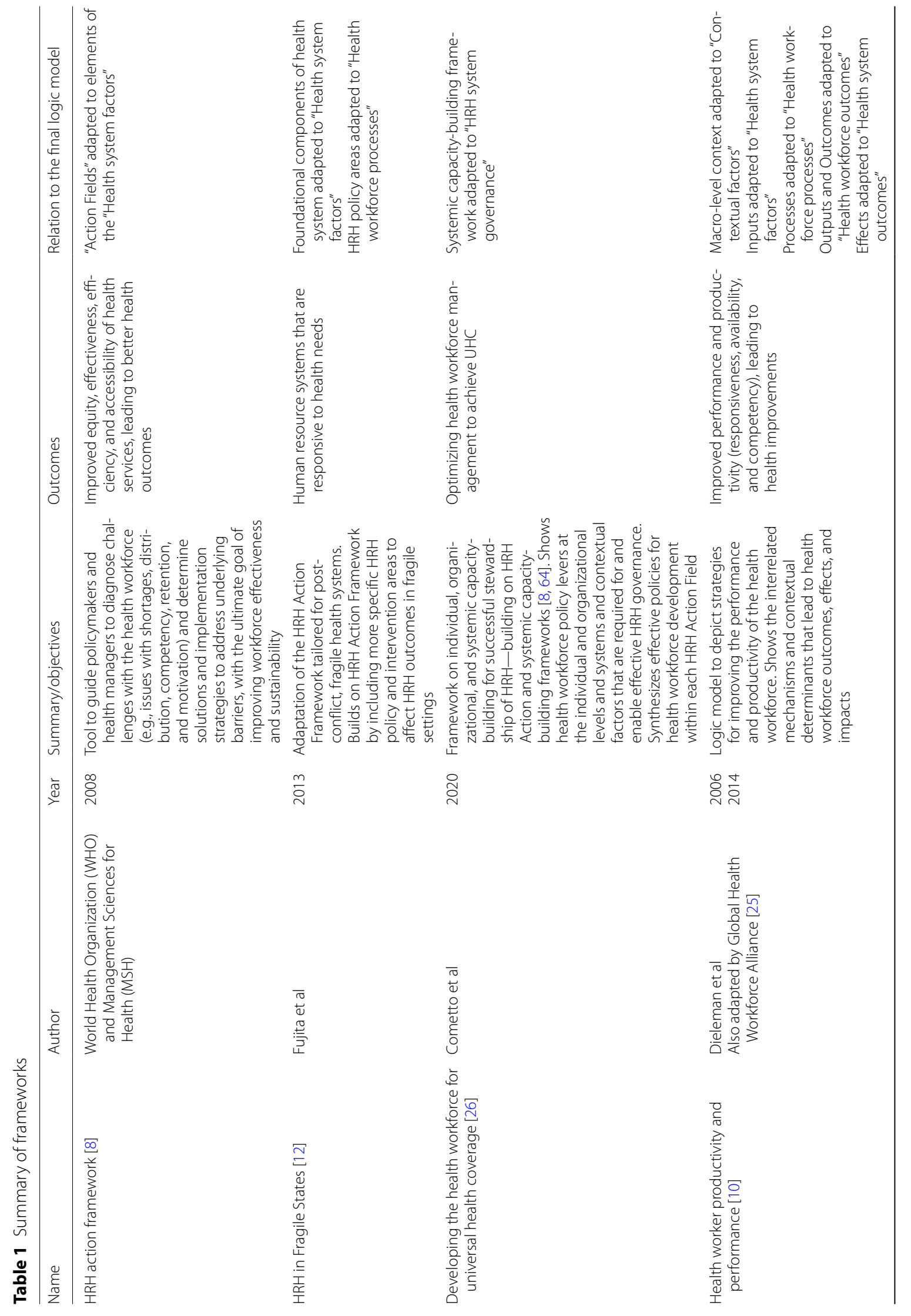




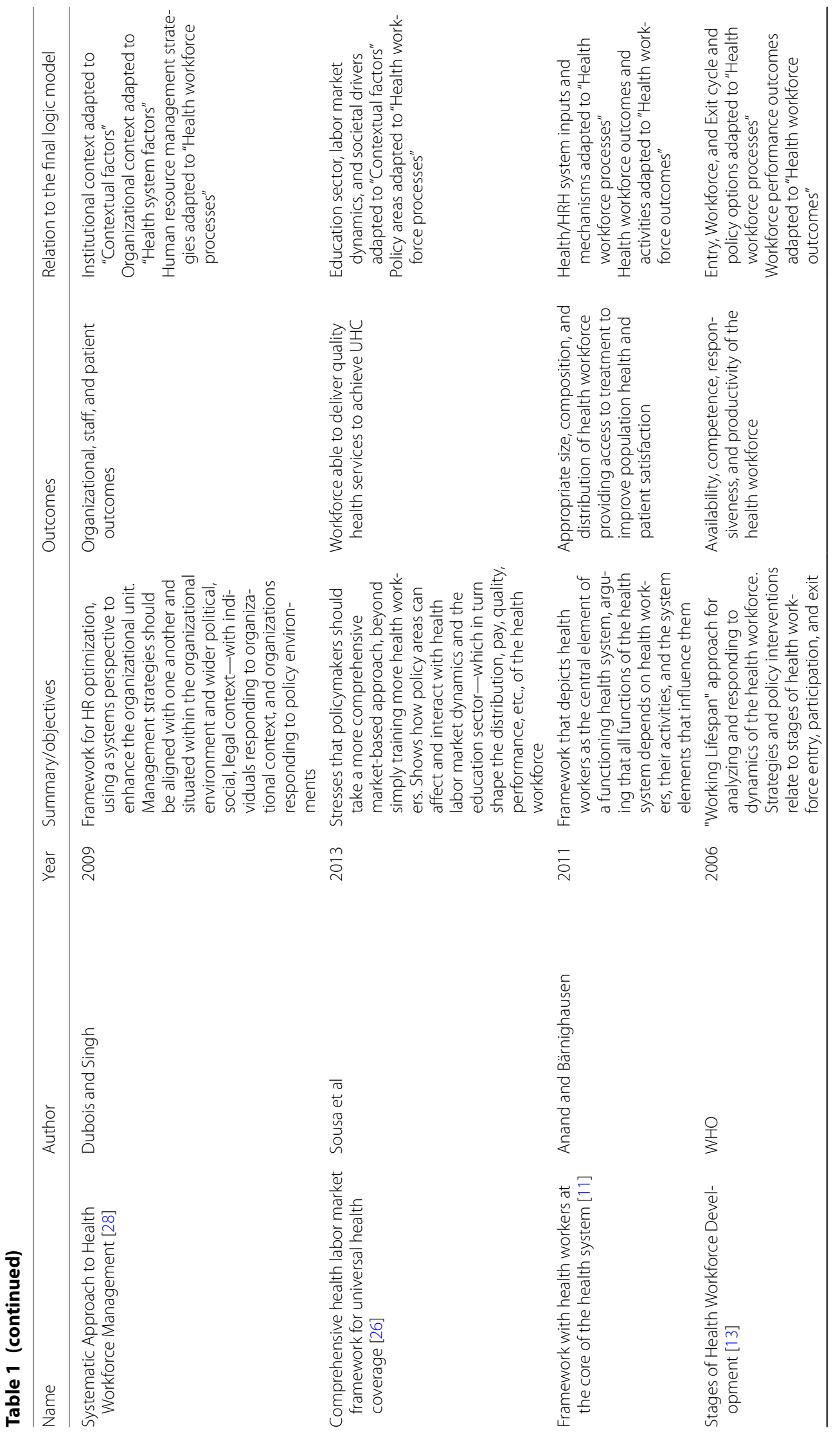




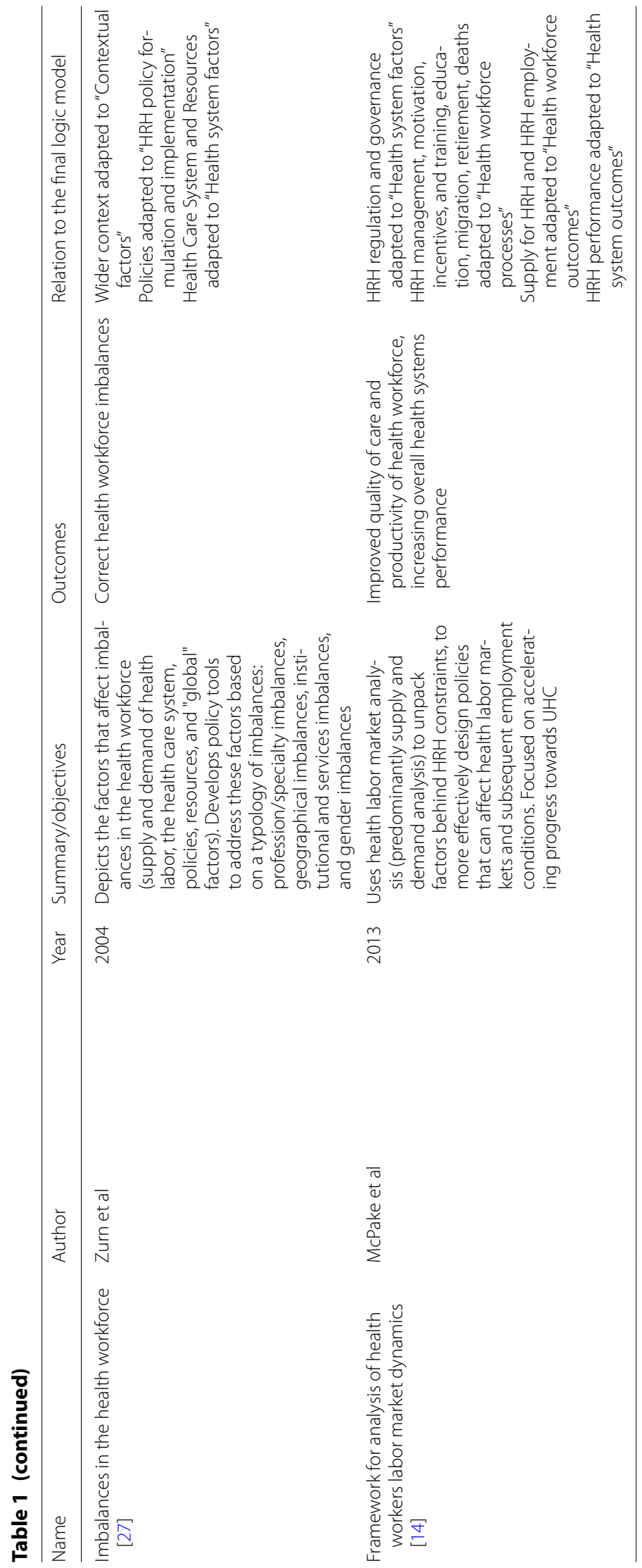




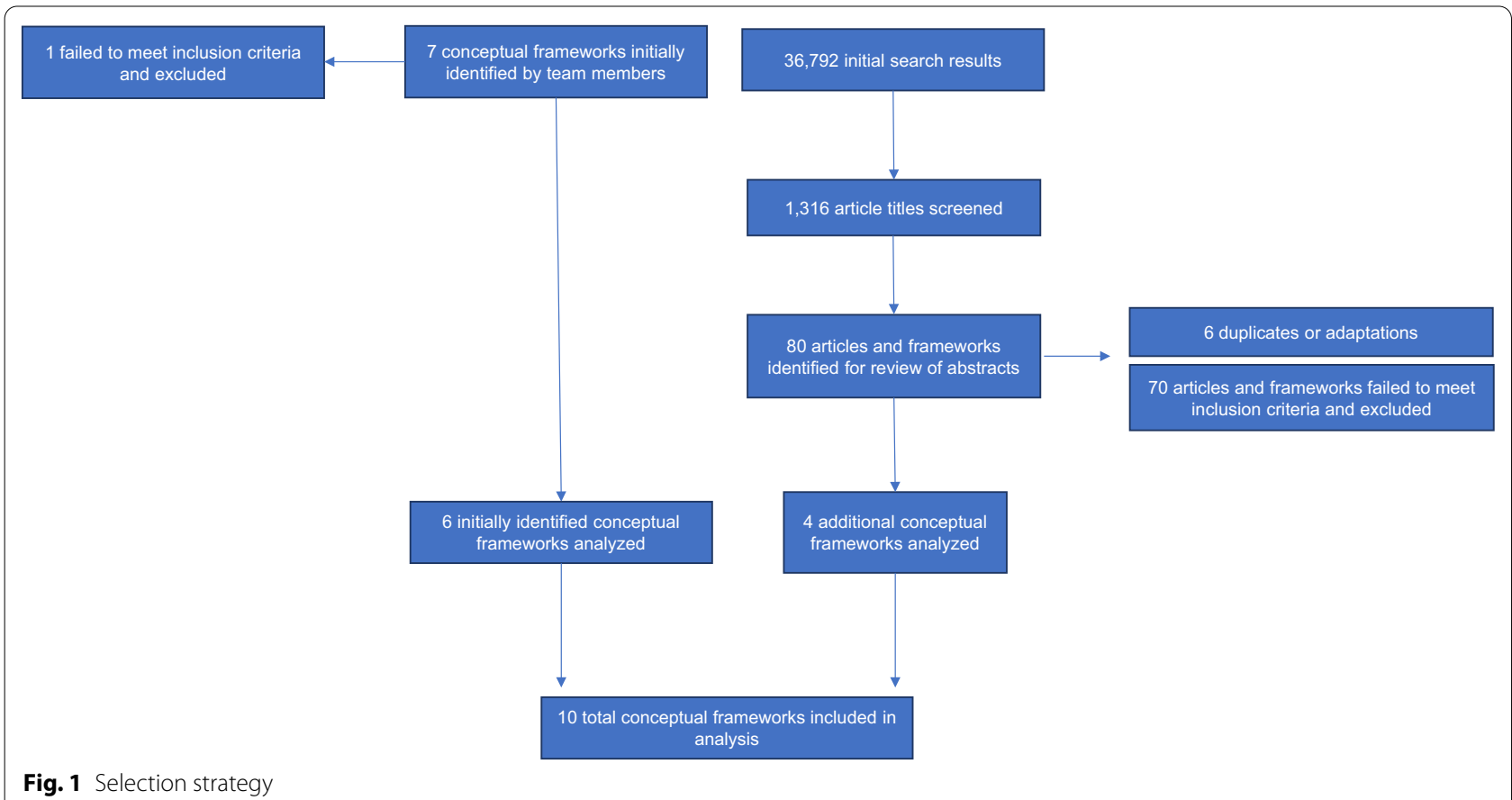

tion and coordination within and across sectors and ministries for multisectoral action; transparency and accountability to government and communities; and corruption within the HRH and broader health systems [35-41]. Electronic human resource management systems (e.g., managing postings, performance, attendance) along with systemic capabilities to use data for workforce planning, regulation, and decision-making are important aspects of governance [36, 37]. Governance is affected by a wider national and international context, and influences HRH policy formulation and implementation.

- HRH policy formulation and implementation: areas of strategy and planning around health workforce objectives; financing allocations and mechanisms to implement HRH interventions and policies; regulatory policy and legislation around medical practice and health workers (e.g., scope of practice for each cadre, and/or expansion of functions); contract compliance of entities engaged to provide health services; and day-to-day operating procedures. Policymaking and implementation are affected by factors of $\mathrm{HRH}$ governance.

Column 3. Health workforce processes: HRH policies affect and are implemented through HRH processes. ${ }^{1}$ $\mathrm{HRH}$ processes and strategies may be implemented across four stages:
- Production of health workers: policies or factors influencing pre-service training of health workers which are generally used to affect the size, composition, competencies, and distribution of HRH. These could include admissions policies or regulation of the quality and distribution of training institutionswhether public or private [43].

- Entry into the health workforce: recruitment strategies and equitable distribution (deployment, reallocation) of the workforce per health system needs and across public and private sectors. Foreign-trained workers may also enter into the health workforce in some countries, dependent on regulations. The stock of health workers trained and the supply of workers currently functioning in a labor market may be different (due to exit from the health labor market, or inability to find work in the health labor market).

- Maintenance and performance: strategies used to retain health workers (particularly in remote underserved area) and manage their performance. These include clinical quality interventions (e.g., job aids or tools to support quality and work flow), performance management systems to measure and develop health worker performance $[44,45]$, in-service training to maintain and strengthen competencies, supportive supervision, and regulation of practice to ensure

\footnotetext{
${ }^{1}$ The Health Worker Life Cycle model [42] is another framework with similar "stages" of the lifecycle, which is based on Sousa et al. [9] and therefore was not included in our results.
} 


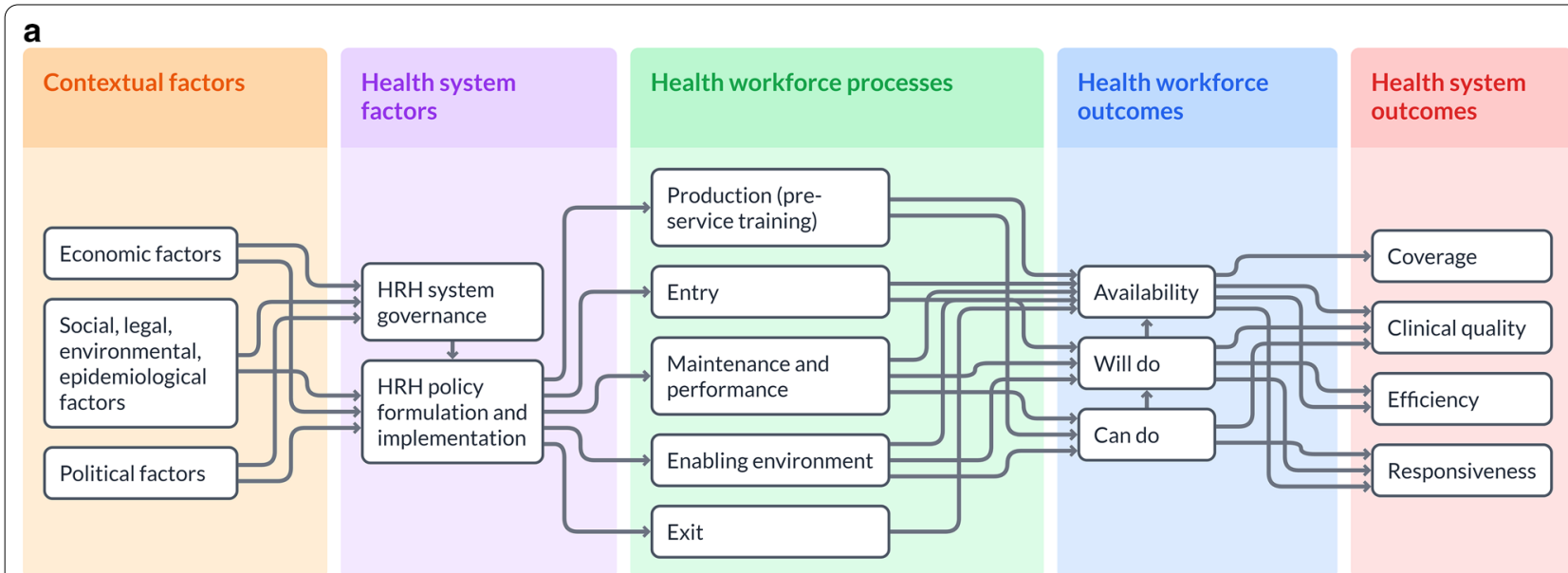

b

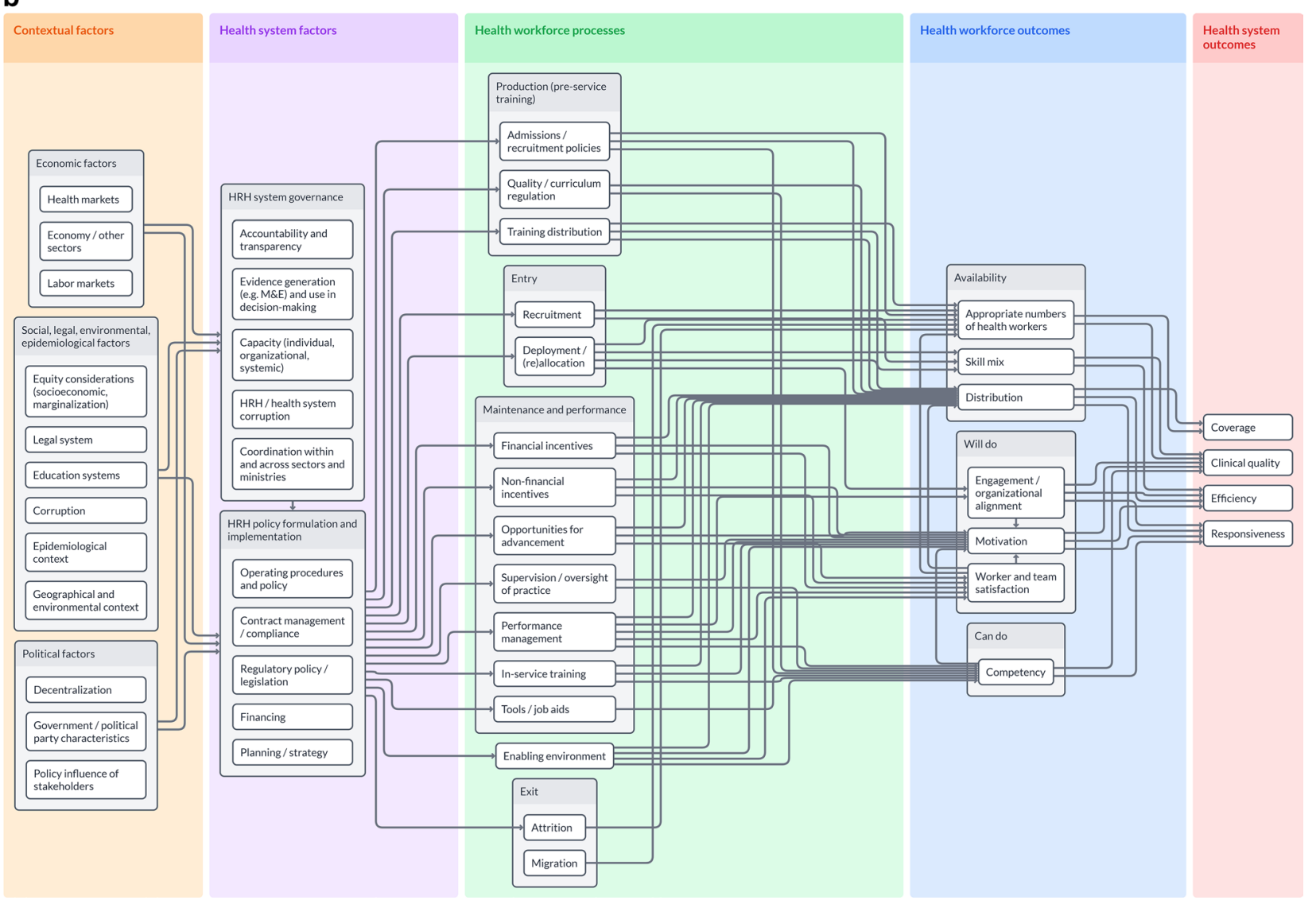

Fig. 2 a High-level logic model. b Detailed logic model

quality of care. In addition, it includes financial and non-financial incentives to promote health worker motivation, performance, and retention in remote underserved areas [46-51].

- Enabling environment: HRH outcomes will be affected by the environment within which the workforce operates. This includes healthcare facilities and infrastructure, availability of supplies and equipment, other health systems building blocks, and living conditions (i.e., road infrastructure, housing, and quality of local schools) [43, 48, 49, 52].

- Health worker exit: exit from the workforce can be a natural progression (e.g., retirement), attrition due to pursuit of alternative careers, migration to locations 
with better living and working conditions, or a lack of sufficient incentives or motivation to remain in the health workforce.

Column 4. Health workforce outcomes: workforce outcomes-specifically, health workforce availability, competency, motivation, engagement, and job satisfaction-are influenced by upstream policies, processes, and contextual factors [32, 46-52].

- Availability: availability of health workers to ensure geographic coverage according to population health requires having appropriate numbers of health workers, equitable distribution across urban and rural areas, and skill-mix across the cadres of healthcare workers.

- Will do: worker and team satisfaction, engagement, and motivation are critical for the competencies of health workers to translate into practice. "Engagement" refers to vigor and energy devoted to one's work; involvement, dedication to, and enthusiasm in work; and absorption and identification with one's work $[53,54]$. Motivation and engagement of health workers support a drive towards quality and improving health outcomes, which supports responsiveness, efficiency, and equity of care $[1,55]$. This is known as the "know-do" gap between provider skills and their application of these skills when delivering services [56]. These factors are also important for influencing retention of health workers.

- Can do: required competencies (knowledge, skills, and attitudes) that are critical for health workers to provide care with high clinical and non-clinical quality, based on designated roles and responsibilities.

Column 5. Health system outcomes: desired health system outcomes focus on "improving health and health equity, in ways that are responsive, financially fair, and make efficient use of available resources" $[1, p .2]$. The ultimate goals of the health workforce are to contribute to these overall health system goals, by enhancing quality, responsiveness, efficiency, and coverage. If health worker performance is combined with a well-functioning health system, the workforce can deliver high-quality health services equitably, leading to improved population health. Specific health system outcomes the workforce contributes to include:

- Quality of service delivery in accordance with predefined standards and protocols, including clinical quality and non-clinical aspects such as safety and equity [2].
- Responsiveness in how the health system meets expectations around provider treatment [57]. This may encompass aspects of non-clinical quality including people-centeredness and patient satisfaction [2].

- Coverage of health workers across both urban and rural areas according to population health needs.

- Efficiency in utilizing financial and non-financial inputs, including appropriate skill-mix based on available human resources.

\section{Discussion}

In this paper, we present a detailed, interactive logic model to inform HRH policy-development and research agendas. The visualizer is online for external input, and we anticipate subsequent revisions as we move forward in gathering further feedback and synthesizing evidence.

The model synthesizes existing frameworks and literature into a user-friendly interface that enables both highlevel and detailed examination of policy areas. We see it complementing existing tools identified in this review $[8-14,26-28]$ by providing granular analyses of relationships and synthesizing underlying literature into a comprehensive model. In our discussion, we consider uses of the current model, describe potential future uses based on additional development, and identify specific use cases, before reviewing limitations.

\section{Current uses}

In its current form, the model enables exploration of the factors driving $\mathrm{HRH}$ outcomes and the contribution of the workforce to health system outcomes.

- Evidence-to-policy process: we see the visualizer being useful in supporting the evidence-to-policy translation process because it provides a visually engaging and comprehensible format for exploring evidence behind key policy questions. Several barriers have been identified in the translation of research for policymaking, including succinct communication of complex methods and ideas, and insufficient time and capabilities for unpacking academic papers and understanding their implications on local context [58-60]. This tool can help address this gap and make the evidence behind policy options more comprehensible for policymakers.

- Education and training: by synthesizing current HRH frameworks and their linkages, this tool can illustrate higher-level policy pathways and relationships between HRH system components. It will allow learners to explore the pathways by which upstream 
factors and external forces affect the HRH lifecycle, and by which $\mathrm{HRH}$ processes contribute to health system outcomes.

\section{Future uses}

We plan to overlay the model with evidence (e.g., research publications, systematic reviews) related to the model's components, subcomponents, and relationships (arrows). Users will be able to click to reveal embedded references to empirical literature. For example, a list of publications could be added to the arrow between financial incentives and distribution of health workers, so a user can understand the empirical evidence behind this relationship.

The model also allows for visual depiction of evidence strength by using boxes and arrows of different weights, sizes, and colors. For example, a relationship that is hypothesized but not yet shown empirically might be represented by a dashed arrow, whereas a linkage that has been demonstrated in numerous studies might be characterized with a thick arrow. This feature could help to inform policy questions and research agendas.

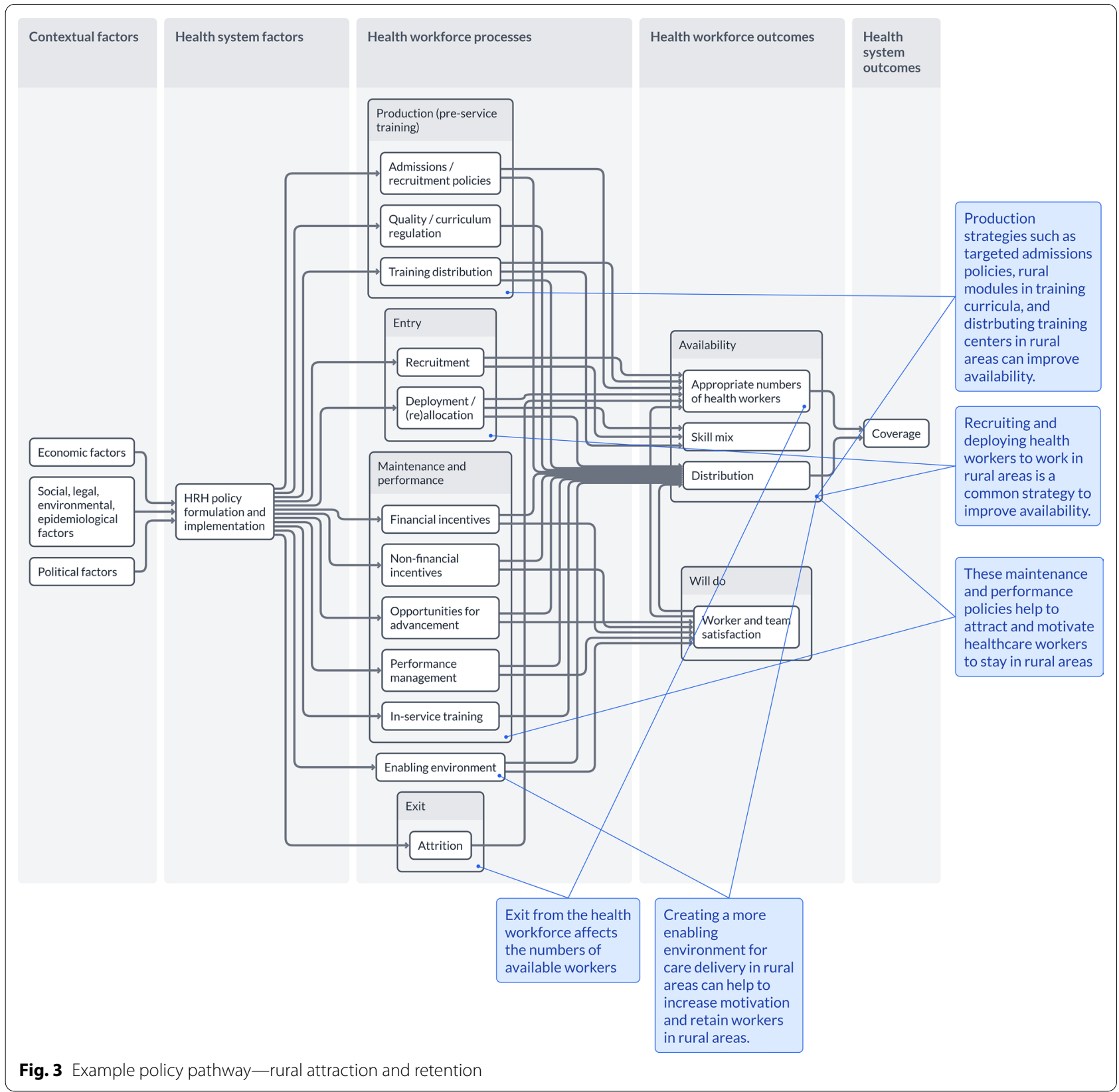


We see multiple opportunities for the visualizer to add value once overlaid with evidence:

- Synthesizing and building health workforce evidence: the visualizer can be used to build consensus around existing and missing evidence on strengthening the health workforce, thereby serving as a dynamic platform that bridges the gap between evidence, policy, and practice. Researchers can use this tool to receive feedback from policymakers for directing future research questions, to ensure they can be of value to policymakers.

- Developing mathematical models: increasingly in global health, stakeholders want to quantify the potential impact of alternative policy options, or the resources required to achieve targets. Mathematical modeling has an important contribution to make in this regard, but until now, most HRH modeling has involved associative models that do not describe the causal pathways between factors [61-63]. Future modeling could involve causal models, in which

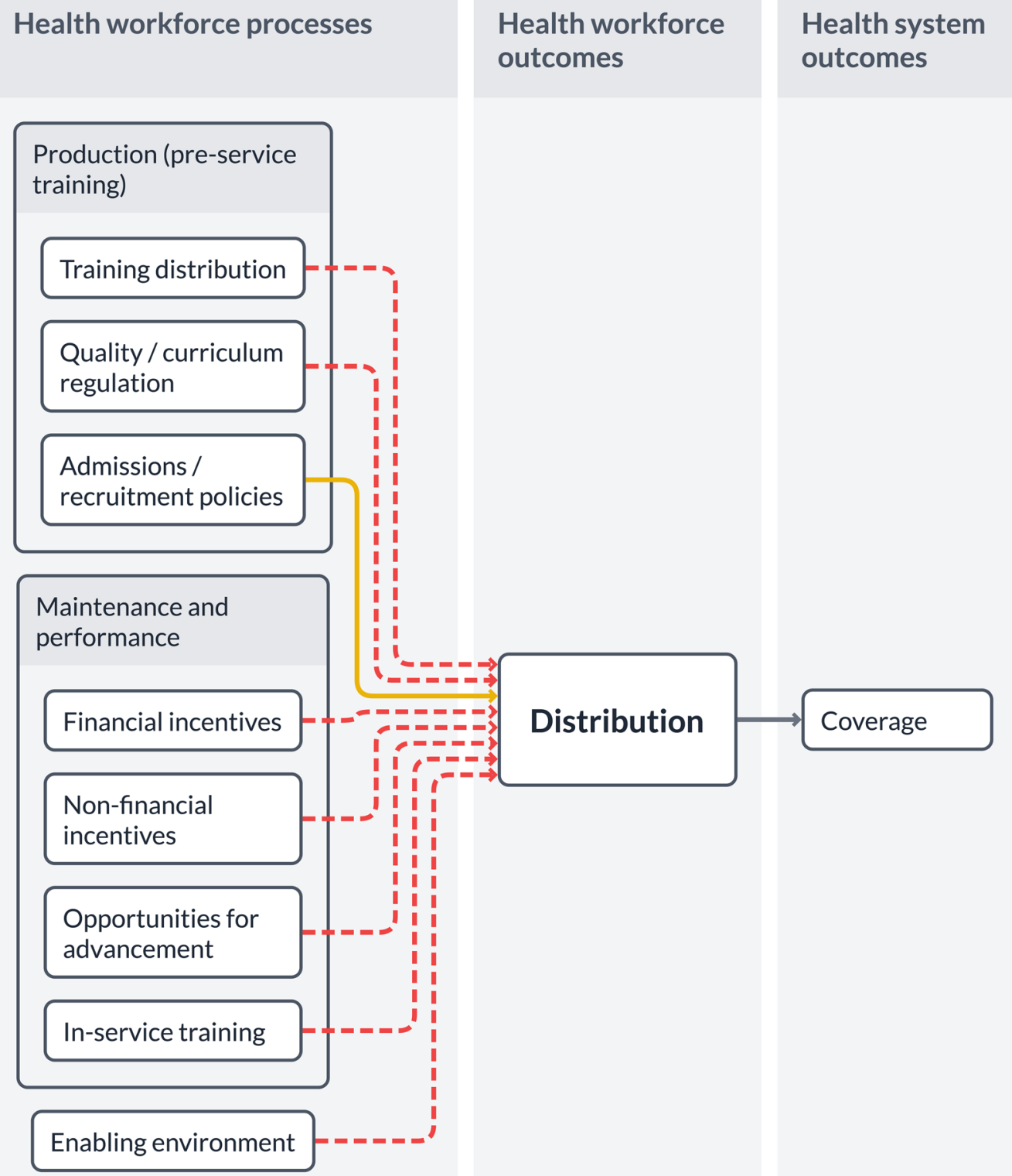

Fig. 4 Example illustration of strength of evidence-rural attraction and retention 
mathematical models are grounded in an a priori understanding of how upstream determinants interact to affect a workforce and achieve health outcomes. This tool can serve as a base for developing such mathematical models.

\section{Illustrative use cases}

In this section, we show two illustrative use cases of the visualizer. The first shows isolation of a "policy pathway" through which contextual factors and policy interventions affect rural health worker attraction and retention. The second describes an evidence map behind rural attraction and retention based on one publication [43].

Figure 3 depicts processes and strategies across the $\mathrm{HRH}$ lifecycle that affect rural distribution, as well as contextual factors that affect policy implementation. Callout boxes help to explain relationships, and related publications are shown when a user clicks on a specific factor or arrow.

Figure 4 shows how the visualizer can be used to map evidence. We have laid out the evidence portrayed in the WHO's policy recommendations for attracting and retaining healthcare workers in rural areas [43]. The dotted red line means "low" or "very low" quality of evidence, while a solid orange line means "moderate" quality of evidence.

These examples show the multiple potential uses for the visualizer platform, both now and in the future as evidence is mapped onto the model.

\section{Limitations}

This analysis and the visualizer have limitations. Our review focused on a subset of databases and English-language publications, and therefore might have omitted relevant frameworks. Further, we recognize it is challenging to capture system complexity within a two-dimensional model. While a logic model requires components to flow from inputs to outcomes in a linear manner, reality is more complicated, with systems interactions and causal loops between upstream and downstream factors, and adjustments over time. For example, the model does not show context and governance's direct effects on the other areas of the model-but rather show their impacts as mediated through policy formulation and implementation. Bringing in these feedback loops would add significant complexity to the model, but may detract from its ability to cleanly depict evidence.

\section{Conclusion}

We built on existing research and conceptual frameworks to create a detailed, interactive logic model that shows the drivers of health workforce performance, and how an effective health workforce contributes to health system goals. The model allows users to see the policy levers and contextual factors that affect HRH processes and outcomes. We hope the tool will help researchers map out the concepts and literature within their area of study, and better understand the available evidence and research gaps. Our goal is to develop a collaborative tool for policymakers, academics, and practitioners, to help illuminate the field of HRH research, and build a shared understanding of steps to achieve health for all.

\section{Abbreviations}

DAG: Directed acyclic graph; HRH: Human resource for health; LiST: Lives Saved Tool; LMIC: Low- and middle-income countries; SVG: Scalable vector graphics; UHC: Universal health coverage; WHO: World Health Organization.

\section{Acknowledgements}

The authors acknowledge Krishna Rao and Ligia Paina from the Johns Hopkins Bloomberg School of Public Health for their assistance in reviewing and providing feedback on the logic model.

\section{Authors' contributions}

SB, TR, SH, UL, and VS conceptualized the study and developed the search terms. SS conducted the literature review, developed the analysis tools, extracted data from the conceptual frameworks, and wrote the initial manuscript draft. TR developed the online visualization tool. SB, TR, SH, UL, VS, and SS contributed to the selection of frameworks, development of the analysis tools and logic model, and manuscript drafting. All authors read and approved the final manuscript.

\section{Funding}

Initial financial support for the development of this model was provided by the Bill and Melinda Gates Foundation via a grant to the University of Manitoba and a sub-award to the Johns Hopkins University (Grant ID\# OPP1161434). The funding body had no role in the study design, data collection, analysis, and interpretation, and manuscript development.

\section{Availability of data and materials}

Logic model visualizer available online [29].

Ethics approval and consent to participate

Not applicable.

\section{Consent for publication}

Not applicable.

\section{Competing interests}

The authors declare that they have no competing interests.

\section{Author details}

1 Johns Hopkins Bloomberg School of Public Health, 615 N. Wolfe Street, Baltimore, MD 21205, USA. ${ }^{2}$ University of British Columbia, Vancouver, BC, Canada.

Received: 5 February 2021 Accepted: 18 February 2021

Published online: 12 March 2021 


\section{References}

1. WHO. Everybody's business: strengthening health systems to improve health outcomes. WHO's framework for action. Geneva: World Health Organization; 2007

2. WHO. Global strategy on human resources for health: workforce 2030. Geneva: World Health Organization; 2016.

3. Chen L, Evans T, Anand S, Ivey Boufford J, Brown H, Chowdhury M, et al. Human resources for health: overcoming the crisis. Lancet. 2004:364:1984-90.

4. Martínez J, Martineau T. Rethinking human resources: an agenda for the millennium. Health Policy Plan. 1998;13(4):345-58.

5. Chopra M, Munro S, Lavis JN, Vist G, Bennett S. Effects of policy options for human resources for health: an analysis of systematic reviews. Lancet. 2008:371(9613):668-74

6. Lassi ZS, Musavi NB, Maliqi B, et al. Systematic review on human resources for health interventions to improve maternal health outcomes: evidence from low- and middle-income countries. Hum Resour Health. 2016;14:10.

7. Rowe AK, Rowe SY, Peters DH, Holloway KA, Chalker J, Ross-Degnan D. Effectiveness of strategies to improve health-care provider practices in low-income and middle-income countries: a systematic review. Lancet Glob Health. 2018;6(11):e1163-75.

8. World Health Organization and Management Sciences for Health. HRH action framework. In: Capacity Project, Global Health Workforce Alliance. United States Agency for International Development, World Health Organization; 2007. http://www.capacityproject.org/framework/. Accessed 26 Feb 2020.

9. Sousa A, Scheffler RM, Nyoni J, Boerma T. A comprehensive health labour market framework for universal health coverage. Bull World Health Organ. 2013;91(11):892-4.

10. Dieleman M, Harnmeijer JW. Improving health worker performance: in search of promising practices. Geneva: World Health Organization; 2006.

11. Anand S, Bärnighausen T. Health workers at the core of the health system: framework and research issues. Health Policy (Amsterdam, Netherlands). 2012;105(2-3):185-91.

12. Fujita $\mathrm{N}$, Zwi AB, Nagai M, Akashi H. A comprehensive framework for human resources for health system development in fragile and postconflict states. PLoS Med. 2011;8(12):e1001146.

13. WHO. Stages of health workforce development. In: WHO World Health Report. Word Health Organization; 2006. https://www.who.int/hrh/tools/ en/. Accessed 26 Feb 2020.

14. McPake B, Maeda A, Araújo EC, Lemiere C, El Maghraby A, Cometto G. Why do health labour market forces matter? Bull World Health Organ. 2013;91(11):841-6.

15. Frimpong JA, Helleringer S, Awoonor-Williams JK, Yeji F, Phillips JF. Does supervision improve health worker productivity? Evidence from the Upper East Region of Ghana. Trop Med Int Health. 2011;16(10):1225-33.

16. Rowe AK, Onikpo F, Lama M, Osterholt DM, Rowe SY, Deming MS. A multifaceted intervention to improve health worker adherence to integrated management of childhood illness guidelines in Benin. Am J Public Health. 2009;99(5):837-46.

17. Humphreys J, Wakerman J, Kuipers P, Wells B, Russell D, Siegloff S, Home K. Improving workforce retention: developing an integrated logic model to maximise sustainability of small rural and remote health care services. Canberra: Australian Primary Health Care Research Institute (APHCRI), The Australian National University; 2009.

18. Agarwal S, Sripad P, Johnson C, et al. A conceptual framework for measuring community health workforce performance within primary health care systems. Hum Resour Health. 2019;17:86.

19. Johns Hopkins Bloomberg School of Public Health. The Lives Saved Tool. Baltimore, MD: Johns Hopkins University; 2020. https://listvisualizer.org/. Accessed 25 Sept 2020

20. Celhay OJ, Silal SP, Maude RJ, Gran Mercado CE, Shretta R, White LJ. An interactive application for malaria elimination transmission and costing in the Asia-Pacific. Wellcome Open Res. 2019:4:61.

21. Mittag $\mathrm{H}$-J. Interactive visualisation tools for exploratory data analysis and policy monitoring [note]. Indicators Group of the Employment Committee, European Commission, Directorate-General: "Employment, social affairs and equal opportunities", Brussels, Belgium; 2005. https://mitta g-statistik.de/publikationnen/Note-DG-EMPL.pdf. Accessed 30 Nov 2020.

22. Capacity Project. All Resources. No date. https://www.capacityproject org/framework/all-resources/. Accessed 26 Feb 2020.
23. World Health Organization. Health workforce resource center. 2021. https ://www.who.int/hrh/resources/en/. Accessed 26 Feb 2020.

24. CapacityPlus. HRH Global Resource Center. No date. https://www.hrhre sourcecenter.org/taxonomy/term/161.1.html. Accessed 26 Feb 2020.

25. Global Health Workforce Alliance. Improving health worker productivity and performance in the context of universal health coverage: the roles of standards, quality improvement, and regulation. Geneva: World Health Organization; 2014. https://www.who.int/workforcealliance/media/ news/2014/WG7_Productivityandperformance.pdf.

26. Cometto G, Buchan J, Dussault G. Developing the health workforce for universal health coverage. Bull World Health Organ. 2020;98:109-16.

27. Zurn P, Dal Poz MR, Stilwell B, Adams O. Imbalance in the health workforce. Hum Resour Health. 2004;2(1):13.

28. Dubois C, Singh D. From staff-mix to skill-mix and beyond: towards a systemic approach to health workforce management. Hum Resour Health. 2009;7:87.

29. HRH Visualizer. https://hrhvisualizer.org. Accessed 4 Feb 2021

30. Lin G, Palopoli M, Dadwal V. From causal loop diagrams to system dynamics models in a data-rich ecosystem. In: Celi LA, Majumder MS, Ordóñez P, Osorio JS, Paik KE, Somai M, editors. Leveraging data science for global health. Cham: Springer International Publishing; 2020. p. 77-98.

31. Homer JB, Hirsch GB. System dynamics modeling for public health: background and opportunities. Am J Public Health. 2006;96(3):452-8.

32. Liu $X$, Dou L, Zhang H, et al. Analysis of context factors in compulsory and incentive strategies for improving attraction and retention of health workers in rural and remote areas: a systematic review. Hum Resour Health. 2015:13:61.

33. What is corruption?. Transparency International. No date. https://www. transparency.org/en/what-is-corruption. Accessed 20 July 2020.

34. Mitchell A, Bossert T. Chapter 7: Politics and governance in human resources for health. In: Soucat RS, Ghebreyesus TA, editors. The labor market for health workers in Africa: a new look at the crisis. Washington DC: International Bank for Reconstruction and Development/The World Bank; 2013. p. 109-25.

35. Barbazza E, Tello JE. A review of health governance: definitions, dimensions and tools to govern. Health Policy (Amsterdam, Netherlands). 2014;116(1):1-11.

36. Rodríguez DC, Hoe C, Dale EM, et al. Assessing the capacity of ministries of health to use research in decision-making: conceptual framework and tool. Health Res Policy Syst. 2017;15:65.

37. WHO. Health workforce governance and leadership capacity in the African Region: review of human resources for health units in the ministries of health. Geneva: World Health Organization; 2012.

38. Fieno JV, Dambisya YM, George G, Benson K. A political economy analysis of human resources for health $(\mathrm{HRH})$ in Africa. Hum Resour Health 2016;14(1):44.

39. Bennett S, Glandon D, Rasanathan K. Governing multisectoral action for health in low-income and middle-income countries: unpacking the problem and rising to the challenge. BMJ Glob Health. 2018;3:e000880.

40. Gaitonde R. Corruption-taking a deeper Dive; Comment on "We Need to Talk About Corruption in Health Systems." Int J Health Policy Manage. 2019;8(11):672-4.

41. Hutchinson E, Balabanova D, McKee M. We need to talk about corruption in health systems. Int J Health Policy Manage. 2019;8(4):191-4.

42. HRH2030. Health Worker Life Cycle: a health worker-centered approach to the health labor market framework. Arlington, VA: HRH2030; 2018. https://hrh2030program.org/health-worker-life-cycle-approach/. Accessed 30 Nov 2020

43. WHO. Increasing access to health workers in remote and rural areas through improved retention. Geneva: World Health Organization; 2010.

44. Martinez, Javier. Assessing quality, outcome and performance management. Workshop on Global Health Workforce Strategy. Geneva: World Health Organization Department of Organization of Health Services Delivery; 2001. https://www.who.int/hrh/documents/en/Assessing_ quality.pdf.

45. Purohit B, Martineau T. Is the annual confidential report system effective? A study of the government appraisal system in Gujarat, India. Hum Resour Health. 2016;14(1):33.

46. WHO. Guidelines: incentives for health professionals. Geneva: World Health Organization; 2008 
47. Willis-Shattuck M, Bidwell P, Thomas S, Wyness L, Blaauw D, Ditlopo P. Motivation and retention of health workers in developing countries: a systematic review. BMC Health Serv Res. 2008;8:247.

48. Mbemba Gl, Gagnon MP, Hamelin-Brabant L. Factors influencing recruitment and retention of healthcare workers in rural and remote areas in developed and developing countries: an overview. J Public Health Afr. 2016;7(2):565.

49. Lemiere C, Herbst C, Jahanshahi N, Smith E, Souca A. Reducing geographical imbalances of health workers in Sub-Saharan Africa. Washington: The World Bank; 2010.

50. Dolea C, Stormont L, Braichet JM. Evaluated strategies to increase attraction and retention of health workers in remote and rural areas. Bull World Health Organ. 2010;88(5):379-85.

51. Mbemba G, Gagnon M, Paré G, et al. Interventions for supporting nurse retention in rural and remote areas: an umbrella review. Hum Resour Health. 2013;11:44.

52. Dieleman M, Gerretsen B, Van Der Wilt GJ. Human resource management interventions to improve health workers' performance in low and middle income countries: a realist review. Health Res Policy Syst. 2009;7:7.

53. Schaufeli WB. What is engagement? In: Truss C, Alfes K, Delbridge R, Shantz A, Soane E, editors. Employee engagement in theory and practice. London: Routledge; 2013.

54. Lourenção LG, Silva AGD, Borges MA. Levels of engagement in primary health care professionals: a comparative study in two Brazilian municipalities. Escola Anna Nery. 2019;23(3):e20190005.

55. Muthuri R, Senkubuge F, Hongoro C. Determinants of motivation among healthcare workers in the East African Community between 2009-2019: a systematic review. Healthcare (Basel, Switzerland). 2020;8(2):164
56. Mohanan M, Vera-Hernández M, Das V, et al. The know-do gap in quality of health care for childhood diarrhea and pneumonia in rural India. JAMA Pediatr. 2015;169(4):349-57.

57. WHO. The World health report: 2000; Health systems: improving performance. Geneva: World Health Organization; 2000.

58. Green A, Bennett S. Sound choices: enhancing capacity for evidenceinformed health policy. Geneva: World Health Organization; 2007.

59. Parkhurst J. The politics of evidence: from evidence-based policy to good governance. London: Routledge; 2017.

60. Whitty CJ. What makes an academic paper useful for health policy? BMC Med. 2015;13:301

61. Pozo-Martin F, Nove A, Lopes SC, Campbell J, Buchan J, Dussault G, Kunjumen T, Cometto G, Siyam A. Health workforce metrics pre- and post-2015: a stimulus to public policy and planning. Hum Resour Health. 2017;15(1):14.

62. Zhu B, Fu Y, Liu J, et al. Detecting the priority areas for health workforce allocation with LISA functions: an empirical analysis for China. BMC Health Serv Res. 2018;18:957.

63. Speybroeck N, Kinfu Y, Dal Poz M, Evans D. Reassessing the relationship between human resources for health, intervention coverage and health outcomes. Geneva: WHO; 2016.

64. Potter C, Brough R. Systemic capacity building: a hierarchy of needs. Health Policy Plan. 2004;19(5):336-45.

\section{Publisher's Note}

Springer Nature remains neutral with regard to jurisdictional claims in published maps and institutional affiliations.
Ready to submit your research? Choose BMC and benefit from:

- fast, convenient online submission

- thorough peer review by experienced researchers in your field

- rapid publication on acceptance

- support for research data, including large and complex data types

- gold Open Access which fosters wider collaboration and increased citations

- maximum visibility for your research: over $100 \mathrm{M}$ website views per year

At BMC, research is always in progress.

Learn more biomedcentral.com/submissions 